\title{
Geraniin ameliorate experimental acute reflux esophagitis via NF-KB regulated anti-inflammatory activities in rats
}

\author{
Hyeon Hwa Nam ${ }^{1}$, Li Nan ${ }^{1}$, Jin Cheon Park ${ }^{2}$ and Byung Kil Choo ${ }^{1 *}$
}

\begin{abstract}
Repeated reflux of gastric acid and stomach contents into the esophagus leads to esophagus damage, including inflammation, ulcer, and hemorrhage in the epithelium. In this study, we aimed to demonstrate the ameliorating effects of geraniin, a phytochemical in the geraniums, on esophagus damage in an acute reflux esophagitis (RE) rat model. The inflammatory effects of geraniinwas measured by nitric oxide (NO) production and pro-inflammatory protein levels in lipopolysaccharide (LPS)-induced RAW 264.7 cells. To evaluate the protective effects of geraniin on damaged esophagus tissue in RE rats, the rats were divided into the following groups: normal control; RE-induced control; RE rats pretreated with geraniin 15 and $30 \mathrm{mg} / \mathrm{kg}$ body weight; and RE rats pretreated with ranitidine $30 \mathrm{mg} /$ $\mathrm{kg}$ body weight as a positive control. The lesion area of esophagus was determined by the Image J program, and histological changes were examined by hematoxylin and eosin staining of rat esophageal tissue. The expression of proinflammatory proteins, cytokines, and tight junction proteins involved in esophagus damages was determined using western blotting of esophageal tissue. Geraniin revealed that anti-inflammatory effects against LPS-induced cells by significantly decreasing NO production and iNOS proteins level. Additionally, the results showed that improvement effects of geraniin on esophagus damages in RE induced rats. The expression of inflammatory proteins involved in nuclear factor NF-kB signaling pathways significantly decreased and tight junction protein (claudin-4 and claudin-5) was increased in esophageal tissue. We found the potential of geraniin as source of replacement therapy products source for inflammatory and reflux esophagitis disease.
\end{abstract}

Keywords: Acute reflux esophagitis, Anti-inflammatory, Claudin, Esophagus damage, Geraniin, NF-KB

\section{Introduction}

The reflux of gastric acid and stomach contents induces epithelial lesion and cell death in the esophagus, which is associated with inflammatory response caused by inflammatory cell infiltration and pro-inflammatory cytokine expression in damaged tissues $[1,2]$. The usual therapy includes histamine-2 receptor antagonist, proton pump inhibitors, and antacid, which have been used for gastroesophageal reflux disease (GERD); however, the use of these agents is limited by complications such as high

\footnotetext{
*Correspondence: bkchoo@jbnu.ac.kr

1 Department of Crop Science and Biotechnology, Chonbuk National University, Jeonju 54896, Republic of Korea

Full list of author information is available at the end of the article
}

recurrence rate, incomplete recovery of mucosal damages, and esophageal stricture [3].

Claudin, a tight junction protein (TJP) in both endothelial and epithelial cells, has barrier and fence functions and is related to GERD. Barrier dysfunction has been demonstrated in inflammatory bowel disease and gastric tissues, and it is associated with TJP such as claudin, occludin, and ZO-1as well as inflammatory cytokines [4, 5]. In particular, a decrease in claudin-4 protein expression has been observed in epithelial cells in the esophageal mucosa [6-8]. Claudin-5 protein expression has been demonstrated in different types of mucosa and cells, and its expression was changed by the expression of proinflammatory cytokines $[4,9]$.

Herbal medicine from plants has been used in healing various diseases owing to its long history in clinical 
practice as well as therapeutic effects $[10,11]$. Recently, the protection effects of Xuanfudaizhetang has been proved in rats with $\mathrm{RE}$ via increasing the $\mathrm{pH}$ value of the esophagus and reducing inflammation stimulation [7]. Artemisia campestris L. extracts have shown protective effects on gastric acid reflux-induced esophageal mucosal injuries [2]. The beneficial effects of Morinda citrifolia fruit extract and its biomarker scopoletin on RE and gastric ulcer in rats have been reported [12].

Geraniin, the main polyphenolic compound of geraniums [11, 13], was first isolated from Geranium thunbergii [14]. The beneficial effects of geraniin, including antiinflammatory and anti-cancer effects in LPS-induced macrophages by inhibiting NF- $\mathrm{kB}$ and Nrf2 signaling pathways, as well as its antioxidant activities, have been reported [14-16]. However, the ameliorating effects of geraniin on esophageal damages in RE via anti-inflammatory activities have not been reported. In the study, we aimed to investigate the ameliorating effects of geraniin on inflamed esophageal mucosa by regulating proinflammatory cytokines, proteins, and TJP in a rat model of RE.

\section{Materials and methods Chemicals}

Geraniin was purchased from Chengdu Biopurify Phytochemicals Ltd. (Chengdu, China). Dulbeco's modified eagle's media (DMEM), fetal bovine serum (FBS) and penicillin/streptomycin purchased $(\mathrm{P} / \mathrm{S})$ from Wel Gene (St. Namchen, Gyeongsan, Korea). Cytotoxicity Kit (EZ-Cytox) bought from Dogenbio (Seoul, Korea). Ranitidine, LPS, dimethyl sulfoxide (DMSO), sulfanilamide, $\mathrm{N}$-(1-naphthyl) ethylene-diamine dihydrochloride (NED), 4-(2-Hydroxyethyl) piperazine-1-ehanesulfonic acid (HEPES), potassium chloride, hematoxylin, eosin and protease inhibitor (PI) purchased from SigmaAldrich (St. Louis, MO, USA). Bovine serum albumin (BSA) protein kit bought from Bio-Rad Laboratories (Hercules, CA, USA). Primary antibodies lamin B from Cell Signaling (Danvers USA), inducible nitric oxide synthase (iNOS), cyclooxygenase (COX-2), $\beta$-actin, tumor necrosis factor alpha (TNF- $\alpha$ ), interleukin 1 beta (IL-1 $\beta$ ), claudin-4, claudin-5, phospho-IkB- $\alpha$ and phospho-NFkB purchased from Santa Cruz (Dallas, TX, USA). The secondary antibodies goat anti-rabbit, goat anti-mouse and western blotting luminal reagent purchased from Santa Cruz (Dallas, TX, USA).

\section{Cell culture}

Raw 264.7 macrophage cell line was bought from the American Type Culture Collection (ATCC, Rockville, MD, USA). Cells were grown in DMEM supplemented with $10 \% \mathrm{FBS}$ and $1 \% \mathrm{P} / \mathrm{S}$ in $\mathrm{CO}_{2}$ incubator $\left(37^{\circ} \mathrm{C}, 5 \%\right.$
$\mathrm{CO}_{2}$ ) (SANTO, Sakata, Japan). The cells were cultured for 1 week and replaced every 2 days. The cultured cells were pretreated with different concentrations $(0,50$ and $100 \mu \mathrm{M})$ of geraniin for $1 \mathrm{~h}$ and then incubated with $1 \mu \mathrm{g} /$ $\mathrm{mL}$ LPS for $24 \mathrm{~h}$.

\section{Cell viability and optical morphological transformation}

We identified the impact of geraniin on Raw 264.7 cells via measurement a cytotoxicity and morphology changes. The cells were plated in 96 -well plates $\left(1 \times 10^{6}\right.$ cells/well $)$ and 6 -well plates $\left(5 \times 10^{5}\right.$ cells/well $)$ treated with different concentrations $(0,50$ and $100 \mu \mathrm{M})$, followed by cotreatment with LPS $(1 \mu \mathrm{g} / \mathrm{mL})$ for $24 \mathrm{~h}$. Cell viability was measured by a cytotoxicity assay kit, and the absorbance was measured at $540 \mathrm{~nm}$ using an enzyme-linked immunosorbent assay (ELISA) plate reader (Multiscan Spectrum, Thermo Scientific, Vantaa, Finland). To observation of Raw 264.7 cells morphology transformation, the image of treated cells was captured by an inverted microscope (ECLIPSE TS200, Nikon, Japan) at fixed $200 \times$ magnification.

\section{NO production in Raw 264.7 cells}

The cell culture plate conducted centrifugation process at $2500 \mathrm{rpm}, 5 \mathrm{~min}$. And then, $50 \mu \mathrm{L}$ of the cell culture supernatant was mixed with $50 \mu \mathrm{L} 1 \%$ sulfanilamide, and $0.1 \%$ NED incubated at $24{ }^{\circ} \mathrm{C}$ for $10 \mathrm{~min}$. The absorbance at $540 \mathrm{~nm}$ was measured in an ELISA reader (Multiscan spectrum). The NO production in the samples was determined using sodium nitrite serial dilution standard curve.

\section{Animal model and management}

The 7-week-old SD rats were maintained in according to the animal welfare regulation of the Institutional Animal Care and Use Committee (IACUC; CBNU 2017-0078), Chonbuk National University Laboratory Animal Center, South Korea. Rats were provided a randomly supply of food and distilled water and placed in a controlled environment (temperature, $23 \pm 2{ }^{\circ} \mathrm{C}$; humidity, 35-60\%; and photoperiod, 12-h light/dark cycle).

\section{Experimental design and acute reflux esophagitis induction}

The 40 rats were randomly divided into four groups: (1) normal control rats $(n=8)$, (2) reflux esophagitis control rats $(n=8)$, (3) reflux esophagitis rats treated with geraniin $15 \mathrm{mg} / \mathrm{kg}$ body weight $(\mathrm{n}=8)$, and (4) reflux esophagitis rats treated with geraniin $30 \mathrm{mg} / \mathrm{kg}$ body weight $(n=8)$. (5) positive control: reflux esophagitis rats treated with ranitidine $30 \mathrm{mg} / \mathrm{kg}$ body weight $(\mathrm{n}=8)$. After $18 \mathrm{~h}$ fasting, the rats in the geraniin groups were administrated with 15 and $30 \mathrm{mg} / \mathrm{kg}$ geraniin 
90 min prior to the abdominal surgery. The rats were anesthetized using an inhalation anesthesia. A midline laparotomy was performed to expose the stomach, the transitional junction between the forestomach and the corpus were exposed, and then they were subsequently ligated with 3-0 silk thread except to normal control. After $5 \mathrm{~h}$, esophagus samples were collected and kept in $-80{ }^{\circ} \mathrm{C}$ for western blotting analysis and immediately fixed with $10 \%$ neutral-buffered formalin (NBF) for histological analysis.

\section{Esophageal lesion ratio}

The esophagus was rinsed with saline solution, and the remaining tissue was placed on white paper. Then, the dissected esophagus was take pictures using an optical digital camera (Nikon, Tokyo, Japan) and the images were analyzed using the Image J program. The gross esophagus tissue damage ratio was calculated as follows:

Gross esophagus damage ratio (\%) $=$ [width of the area with esophageal tissue damage $\left(\mathrm{mm}^{2}\right) /$ width of the total area of the esophagus $\left.\left(\mathrm{mm}^{2}\right)\right] \times 100$.

\section{Histopathological analysis of esophageal tissue}

Esophagus samples of each rat were collected and immediately fixed in 10\% (NBF). Samples were processed using an auto processor (Excelsior ES, Thermo Scientific, USA). After embedding, paraffin section $(5-\mu \mathrm{m})$ were stained with hematoxylin and eosin (H-E) and mounted on glass slides. Digital images of sample were obtained using a Leica DM2500 microscope (Leica Microsystems, Germany) at a fixed $200 \times$ magnification.

\section{Preparation of cytosol and nuclear fraction of esophagus}

Tissues were homogenized in lysis buffer: containing $10 \mathrm{mM}$ HEPES ( $\mathrm{pH} 7.8$ ), $2 \mathrm{mM}$ magnesium chloride $\left(\mathrm{MgCl}_{2}\right), 10 \mathrm{mM}$ potassium chloride $(\mathrm{KCl})$, and $0.1 \mathrm{mM}$ ethylenediaminetetraacetic acid (EDTA), and then $1 \mathrm{mM}$ dithiothreitol (DTT), $0.1 \mathrm{mM}$ phenylmethylsulfonyl fluoride (PMSF) mixture solution and 10\% NP-40 were added. The nuclear fraction was extracted in lysis buffer (pH 7.4): containing $50 \mathrm{mM}$ HEPES (pH 7.8), $50 \mathrm{mM}$ $\mathrm{KCl}, 300 \mathrm{mM} \mathrm{NaCl}$, 1\% glycerol, 0.1 EDTA, $1 \mathrm{mM}$ PMSF, and PI mixture solution. The protein concentration was measured using a Bio-Rad protein kit.

\section{Western blot analysis}

The proteins $(8 \mu \mathrm{L})$ were separated by 10 and $12 \%$ sodium dodecyl sulfate-polyacrylamide gel electrophoresis (SDS-PAGE), and the separated proteins were transferred to nitrocellulose membranes. The membrane was maintained with 5\% skim milk in phosphate-buffered saline (PBS) solution-1\% Tween 20 for $1 \mathrm{~h}$ at room temperature and incubated with the primary antibodies (1:1000) for overnight at $4{ }^{\circ} \mathrm{C}$. Then, the membrane incubated secondary antibodies $(1: 10,000)$ at $2 \mathrm{~h}$. Bands were detected using western blotting luminal reagent and images were obtained using a ChemiDoc ${ }^{\mathrm{TM}}$ MP imaging system (BioRad, USA).

\section{Statistical analysis}

The statistical analysis was performed using the statistical package of the social sciences (SPSS) software (SPSS Inc., Chicago, IL) using an analysis of variance (ANOVA), followed by Tukey's multiple comparison tests at $p<0.05$.

\section{Results}

\section{Cytotoxicity and optical morphological transformation in Raw 264.7 cells}

The cell viability on LPS $(1 \mu \mathrm{g} / \mathrm{mL})$-induced Raw 264.7 cells cultured in incubator for $24 \mathrm{~h}$ was measured by a cytotoxicity assay kit, to identified the cytotoxicity of geraniin. Geraniin showed does not significant cytotoxicity on Raw 264.7 cells up to concentrations 50 and $100 \mu \mathrm{M}$ (Fig. 1b). In the view of morphological images, we observed the cell transformation such as a swelling formation and cell wall change by inflammation reaction on LPS $(1 \mu \mathrm{g} / \mathrm{mL})$ induced cells compared with untreated cells. However, the morphological change was decreased on LPS-induced cells pre-treated with geraniin 50 and $100 \mu \mathrm{M}$. Also, the result that take a view of morphological transformation of cells showed the inflammation reaction on LPS induced Raw 264.7 cells lead to morphological change. Especially, the cells pre-treated with geraniin $100 \mu \mathrm{M}$ showed most similar shape to normal (Fig. 1a).

\section{NO production and iNOS expression in LPS-induced inflammation in Raw 264.7 cells}

Main pro-inflammatory mediator NO plays a significant role in immune system and it is produced by iNOS during inflammatory responses. Also, iNOS revealed after exposure to pro-inflammatory conditions in the cell and tissue [11]. As shown in Fig. 2, the NO production and iNOS protein expression was hardly observed in the normal group compared to that in the LPS-treated group. In the cells pre-treated with the geraniin $(0,50$ and $100 \mu \mathrm{M})$, NO production was significantly inhibited compared to LPS treated group and the effects were concentrationdependent. In particular, NO production most decreased by over $50 \%$ in cells treated with geraniin $100 \mu \mathrm{M}$. In addiction we used western blotting to determine the suppress effect of geraniin in pro-inflammatory protein iNOS. Data showed that geraniin significantly reduced NO production and iNOS protein activity in Raw 264.7 cells. 


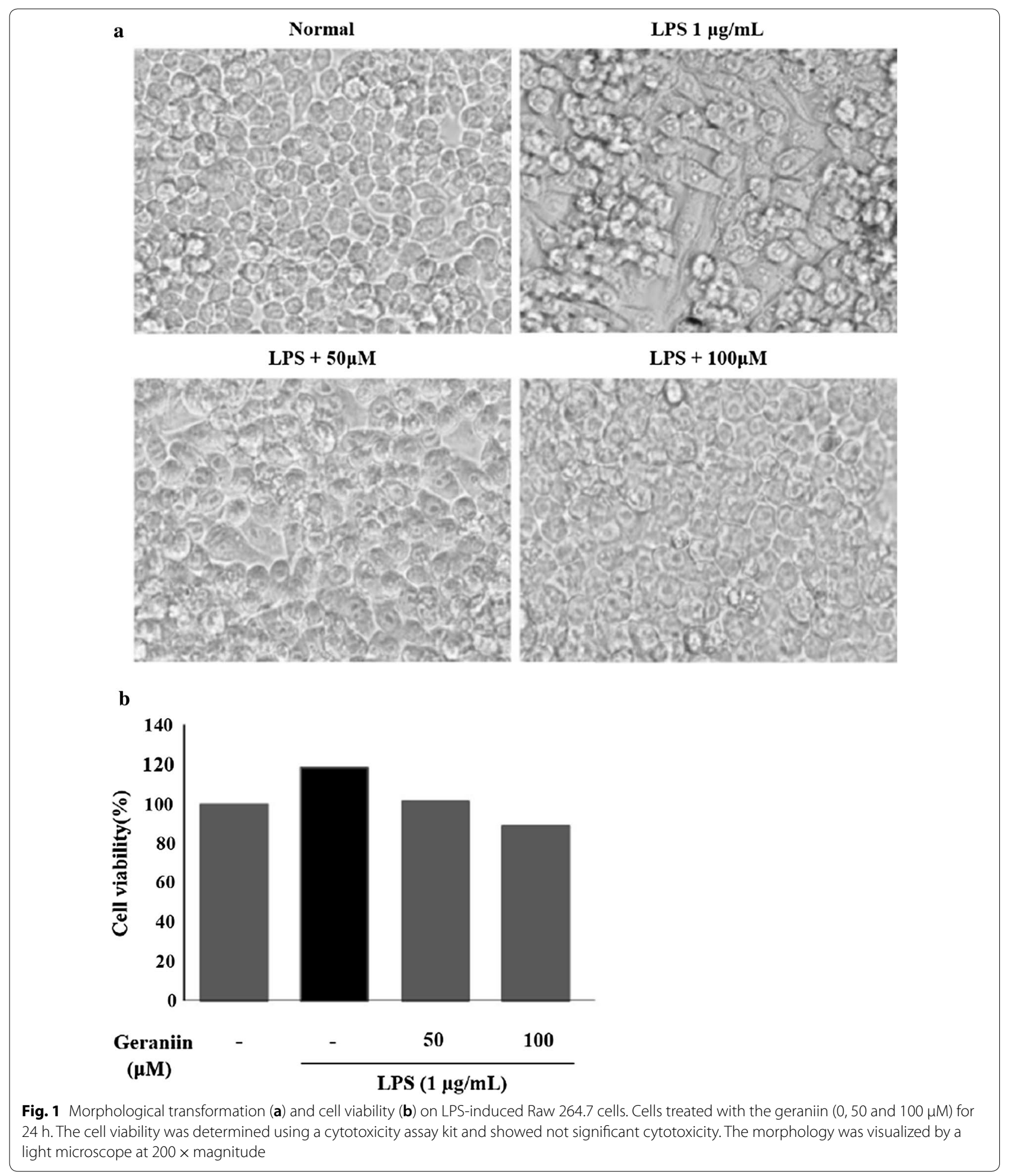



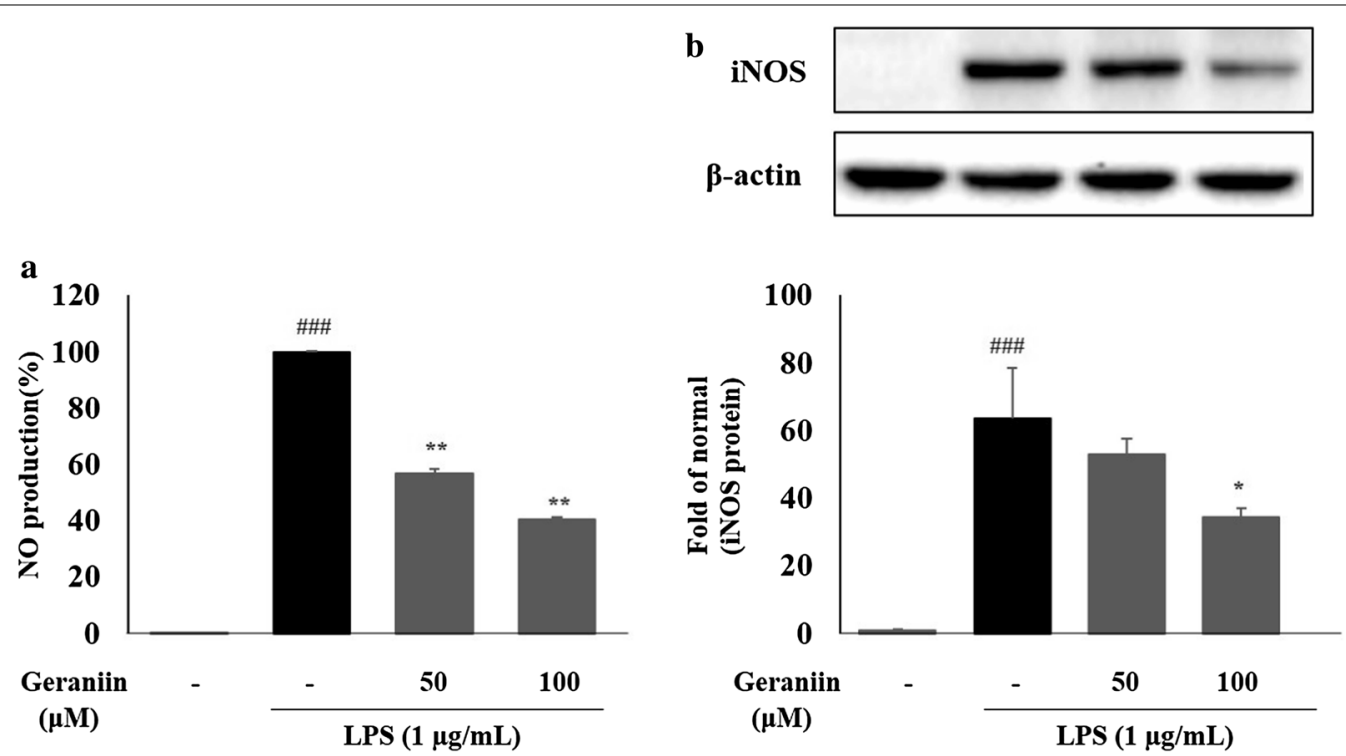

Fig. 2 Inhibition of NO production (a) and expression of iNOS protein (b) in LPS-induced Raw 264.7 cells. Cells pre-treated with geraniin 50 and $100 \mu \mathrm{M}$ for $24 \mathrm{~h}$. Data are mean \pm standard deviation (SD); ${ }^{\# \#} p<0.001$ compared with normal control cells; ${ }^{* *} p<0.01$, and ${ }^{*} p<0.05$ compared with LPS control cells

\section{Changes of esophagus tissue damage in acute RE rats}

To evaluated protective effects of geraniin on reflux esophagitis rats, experimental rats were orally administrated with geraniin (15 and $30 \mathrm{mg} / \mathrm{kg}$ body weight) and ranitidine $30 \mathrm{mg} / \mathrm{kg}$ body weight $90 \mathrm{~min}$ before the surgery. Then, the rats except for those in the normal control group, were subjected to laparotomies to ligate the pylorus and the junction between the forestomach and the corpus [17], and esophageal damage was induced by gastric acid reflux during the ligation. Our data showed that the esophageal tissue of the RE control group showed tissue damages and hemorrhage induced by inflammation compared to the normal control group (Fig. 3). The geraniin $15(15 \mathrm{mg} / \mathrm{kg})$ group showed a reduced incidence of damages and hemorrhage in the esophagus compared to the RE control group. In the $\mathrm{RE}+$ geraniin 30 and ranitidine $(30 \mathrm{mg} / \mathrm{kg})$ group, the esophageal erosions area of rats significantly decreased by more than $80 \%$ and $90 \%$ compared to the RE control group. Therefore, these results indicate that the geraniin has protective effects against esophagus tissue damage in acute RE rats.

\section{Histopathology analysis of esophagus of RE rats}

The esophagus of the normal control group did not exhibit tissue changes while severe damages such as inflammatory cell infiltration and a thin epithelial layer were observed in the mucosa and submucosa of the RE-induced rats. However, we obtained result that the esophagus tissue damage of the RE rats was alleviated to a similar condition to that of the normal group by treatment with geraniin $15,30 \mathrm{mg} / \mathrm{kg}$ and ranitidine $30 \mathrm{mg} /$ $\mathrm{kg}$. The result of histopathology analysis was similar to experimental result which measured a tissue damage area (Fig. 4).

\section{Pro-inflammatory protein expression in esophagus}

Dysregulation of inflammation can induce tissue injuries and wide inflammatory diseases. It is well-known that inflammatory cytokines and stresses lead to increased phosphorylation and activation of activates NF- $\mathrm{B}$. $N F-k B$, main regulator of the production of inflammatory proteins such as iNOS, COX-2, activated by cytokines TNF- $\alpha$ and IL- $1 \beta$ and pathway during immune responses following its dissociation and phosphorylation by IкB- $\alpha$ [18]. In the RE control group, the expression level of both phosphorylated-IкB- $\alpha \quad\left(\mathrm{p}-\mathrm{I}_{\kappa} \mathrm{B}-\alpha\right)$ and phosphorylatedp65 (p-p65) proteins was increased more by tissue damage than they were in the normal control group (Fig. 5). Geraniin was significantly reduce the p-IкB- $\alpha$ and p-p65 proteins compared with RE control. Effect of geraniin $30 \mathrm{mg} / \mathrm{kg}$ treatment was similar to ranitidine $30 \mathrm{mg} / \mathrm{kg}$ on damaged tissue in RE rats. In addition, the inflammatory cytokines and enzymes increased by tissue damage. However, the result showed that geraniin and ranitidine improved the esophageal inflammation by inhibiting the expression of cytosolic, COX-2, TNF- $\alpha$ and IL- $1 \beta$, especially at $30 \mathrm{mg} / \mathrm{kg}$. 

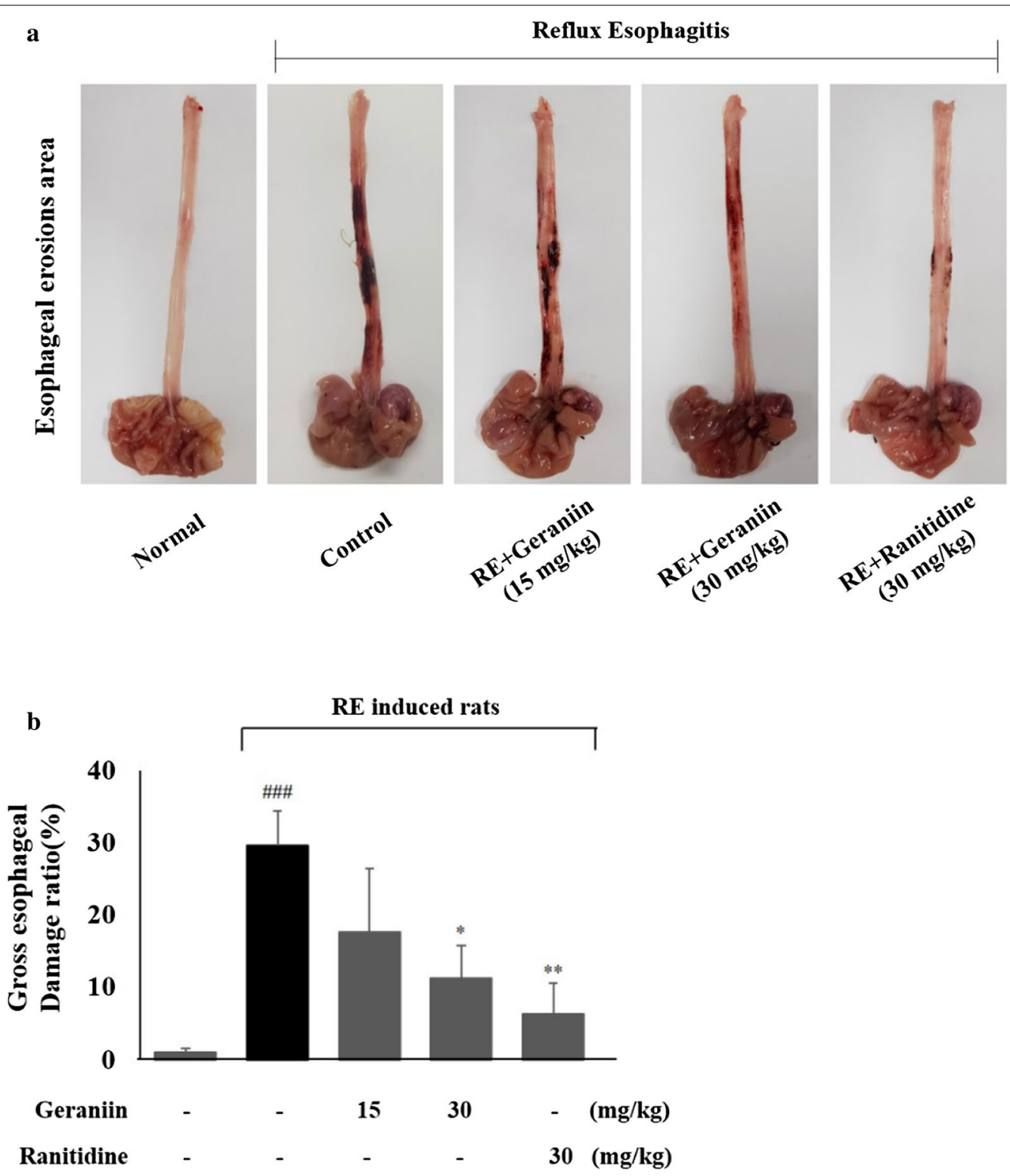

Fig. 3 Gross esophageal erosions area (a) and esophagus ulcer ratio (b) of RE rats. Normal, untreated rats; RE Control, RE rats; RE + geraniin 15 mg/ $\mathrm{kg}$ body weight treated RE rats; RE + geraniin $30 \mathrm{mg} / \mathrm{kg}$ body weight treated RE rats; RE + ranitidine $30 \mathrm{mg} / \mathrm{kg}$ body weight treated RE rats. Data are mean \pm standard deviation (SD); ${ }^{\# \#} p<0.01,{ }^{* *} p<0.01$, and ${ }^{*} p<0.05$ compared with normal control and RE control groups, respectively

\section{Claudin-4 and claudin-5 protein expression in esophagus} Western blot analysis for measurement TJP claudin-4 and claudin-5 result showed in Fig. 6. The expression of claudin-4 and claudin-5 significantly decreased on esophagus in the RE control. However, reduction of expression showed not significantly in the claudin-5. The expression of the TJP was measured the highest in the normal control. We observed the effects of geraniin on TJP on esophagus tissue in RE rat. In this study, as an esophageal erosions decreased, the expression of claudin- 4 and claudin- 5 proteins were increased by concentration-dependent manner on esophagus tissue in a RE rat. We found that the expression of claudin- 4 and claudin- 5 were all increased by concentration-dependent and significantly higher in pretreated ranitidine and geraniin $30 \mathrm{mg} / \mathrm{kg}$ group compared with RE control group. 


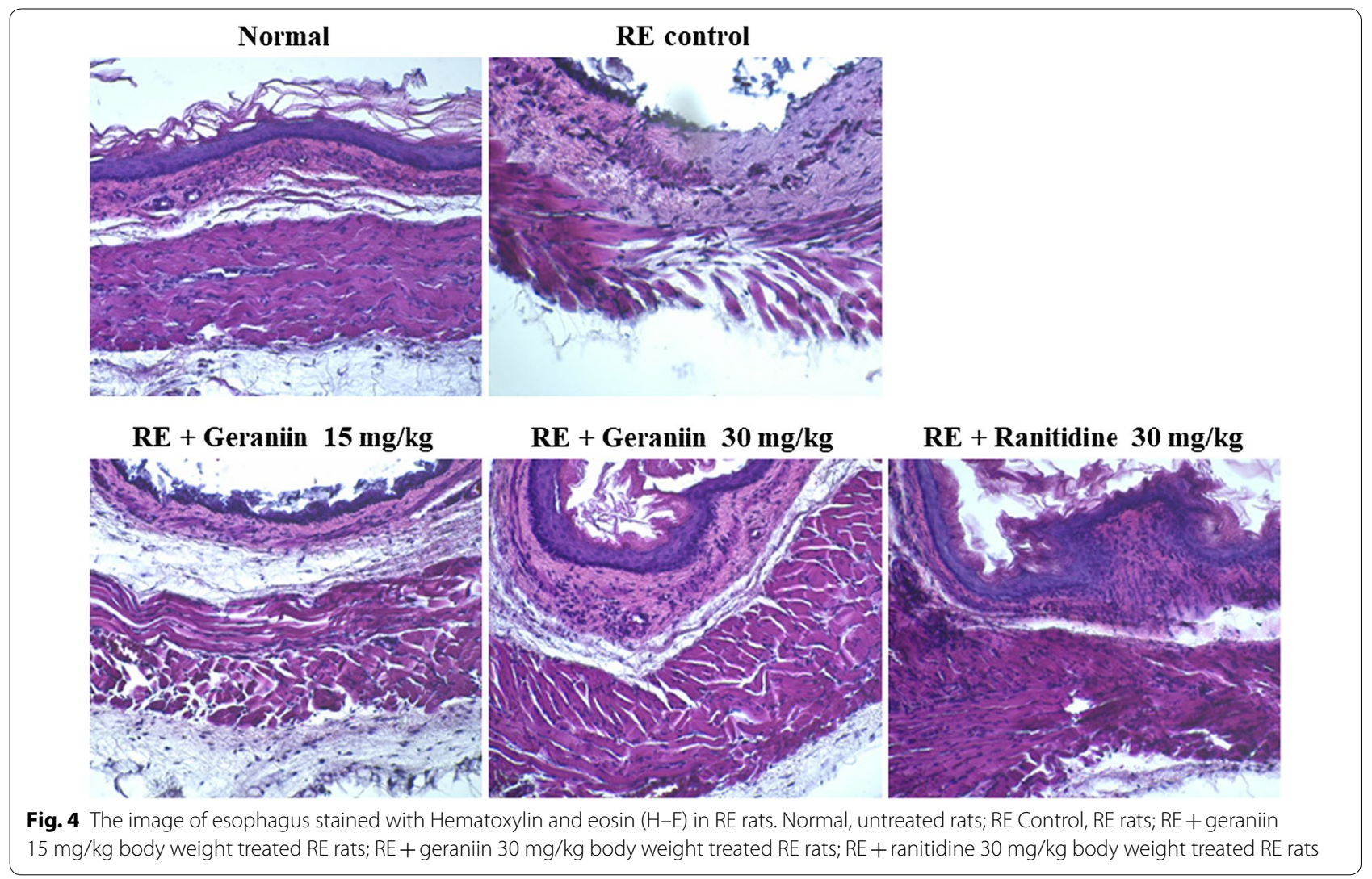

\section{Discussion}

Plant secondary metabolites such as phenolic and flavonoid components have a beneficial activity [19]. Geranium has been used form inflammation, diarrhea and skin rash disease and the antiviral, antioxidant and anti-inflammatory components isolated from Geranium has been accomplished [13, 20]. In addition, many studies of traditional medicine showed geraniin, a main phenolic component of Geranium, has a various biology activity such as anti-inflammatory, anticancer and hepaprotective effect $[11,15,21]$.

In current study, we investigated the biology activity in vitro and in vivo to identify the protective effects of geraniin. The cytotoxicity was investigated to evaluate the application possibility as a safety replacement therapy. Geraniin has no significantly cytotoxicity and on Raw 264.7 cells up to concentrations 50 and $100 \mu \mathrm{M}$. Non-cytotoxic level of geraniin on LPS-induced RAW
264.7 cells and the cytoprotective effect in HepG2 cells have been reported $[11,22]$. In the view of morphological images, cell transformation was significantly induced by LPS compared with untreated cells. However, the morphological change was decreased on LPSinduced cells pre-treated with geraniin 50 and $100 \mu \mathrm{M}$ (Fig. 1).

Inflammatory mediator NO production was hardly increased on LPS treatment. In the cells were pre-treated with geraniin at concentrations of 50 and $100 \mu \mathrm{M}$, NO production was significantly inhibited compared to LPS treated group and the effects were concentrationdependent. In particular, NO production most decreased by over $50 \%$ in cells treated with geraniin $100 \mu \mathrm{M}$. Furthermore, the results indicated geraniin significantly suppressed the expression of inflammatory protein iNOS. All these results, demonstrate a non-cytotoxic and antiinflammatory effects on LPS-induced Raw 264.7 cells.

\footnotetext{
(See figure on next page.)

Fig. 5 Inhibitory effects of geraniin on inflammatory protein and cytokine expression in esophagus. Expression of pro-inflammatory protein TNF-a,

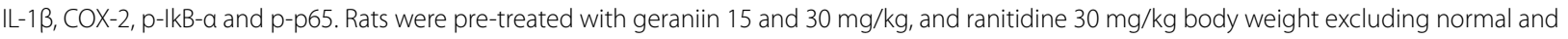
RE control for 90 min before surgery. After $5 \mathrm{~h}$, the esophageal mucosa was cut, and then, the was abdomen open and removed from each rat. Data are mean \pm standard deviation (SD). Significance: ${ }^{\# \#} p<0.01$ and ${ }^{\#} p<0.05$ compared with normal control group; ${ }^{* *} p<0.01$ and ${ }^{*} p<0.05$ compared with RE control group
} 


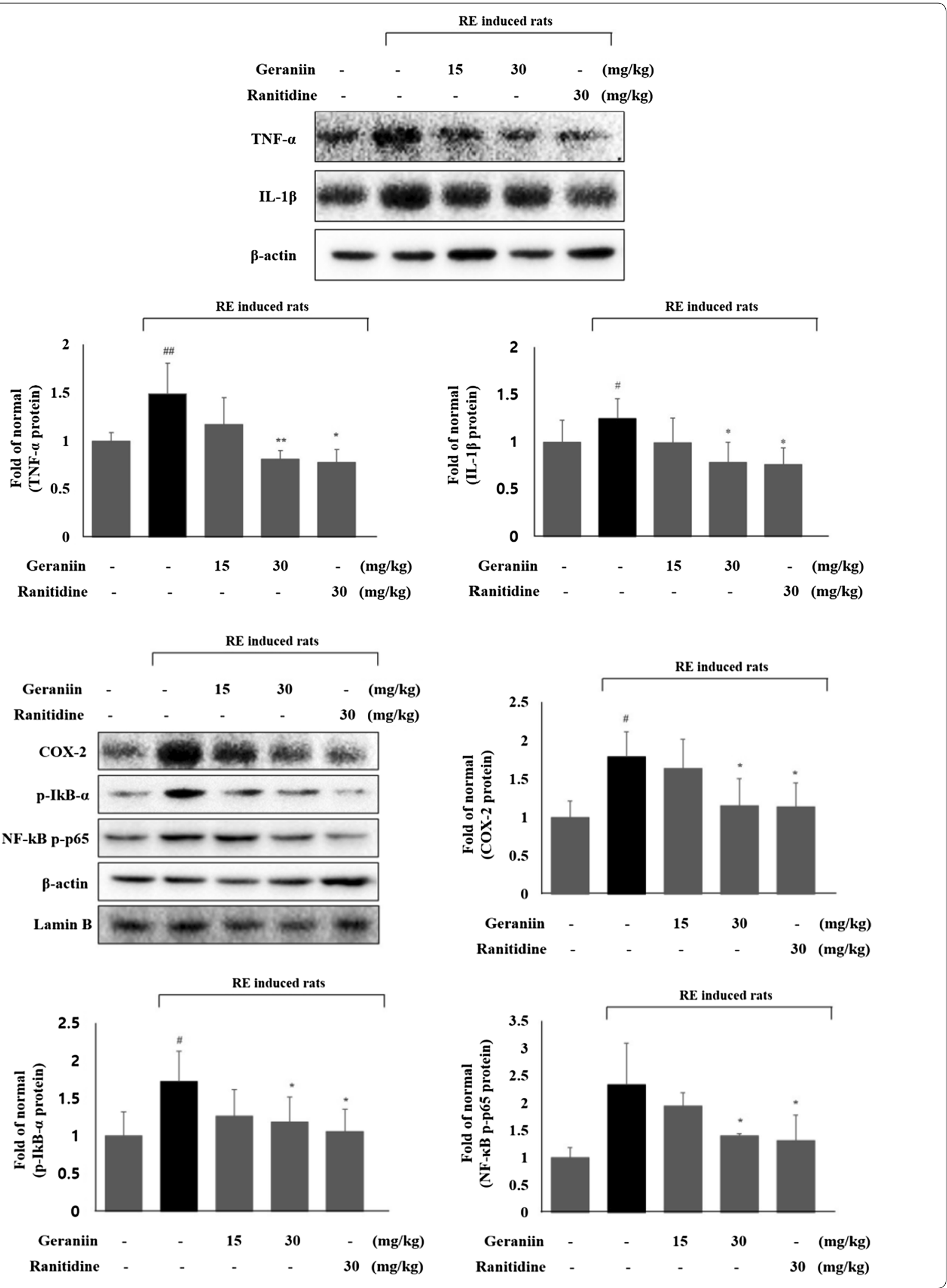



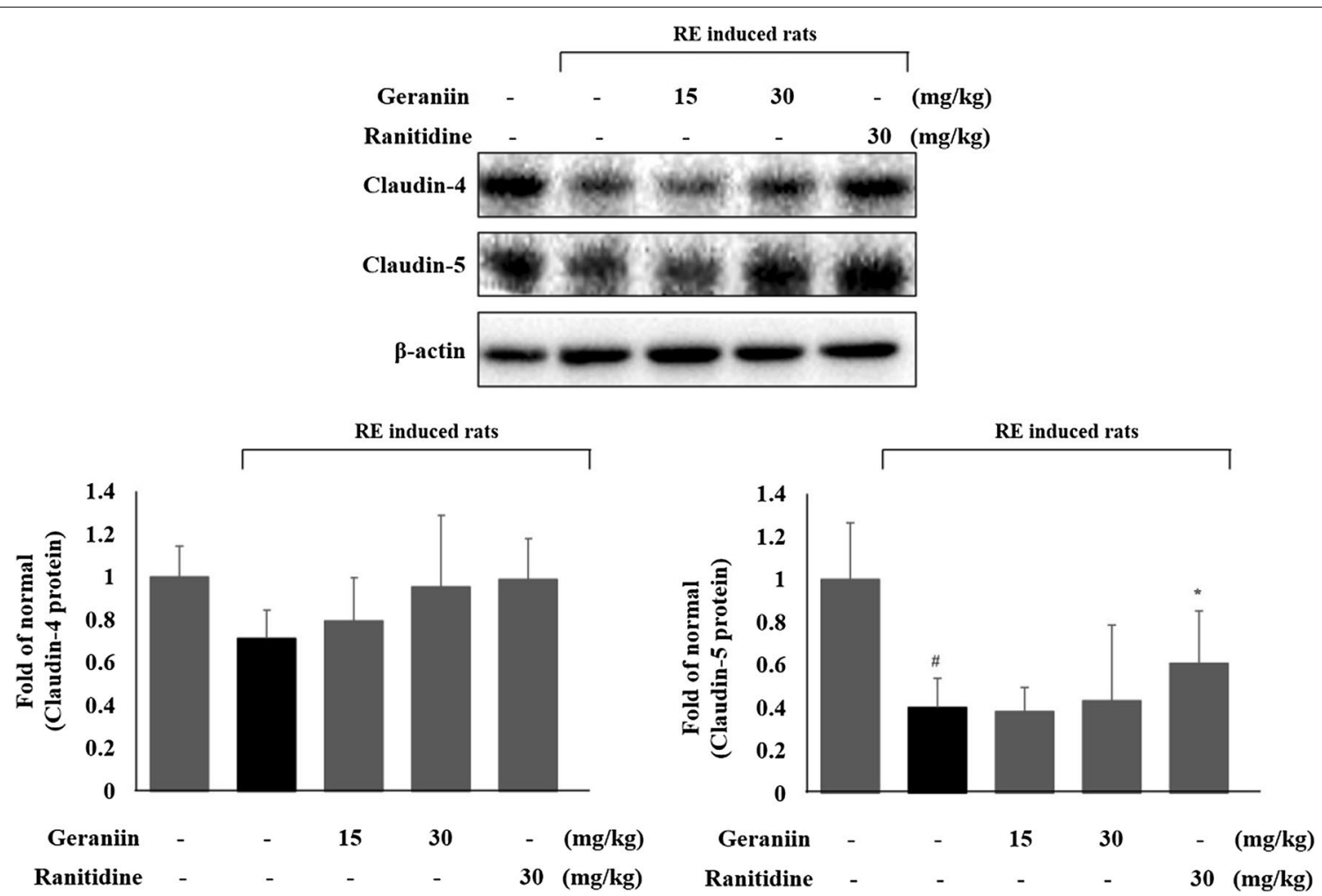

Fig. 6 Effects of geraniin on TJP (claudin-4 and claudin-5) in esophageal damage by RE rats. Rats were pre-treated with 15 and $30 \mathrm{mg} / \mathrm{kg}$ body weight geraniin, and $30 \mathrm{mg} / \mathrm{kg}$ ranitidine excluding normal and RE control for $90 \mathrm{~min}$ before surgery. Then, $5 \mathrm{~h}$ later, the esophageal mucosa was cut, and collected from each rat. Data are mean \pm standard deviation (SD). Significance: ${ }^{\#} p<0.05$ and ${ }^{*} p<0.05$ compared with normal control and RE control groups, respectively

The toxic effects of gastric acid and stomach contents lead to epithelial injury and cell death in esophageal mucosa [1, 23]. To evaluated protective effects of geraniin on reflux esophagitis rats, experimental rats were orally administrated with geraniin $(15$ and $30 \mathrm{mg} /$ $\mathrm{kg}$ body weight) and $\mathrm{H} 2$ inhibitor ranitidine $30 \mathrm{mg} / \mathrm{kg}$ body weight as positive control. Ranitidine, a histamine-2 receptor antagonist, used as a reference drug in study of gastritis and clinical practice [24, 25]. In damage area and histological analysis showed that the esophageal tissue of the RE control group indicated a tissue damages such as hemorrhage, inflammatory cell infiltration and epithelium destruction induced by reflux (Figs. 3, 4). However, these symptoms were markedly decreased by treatment drug ranitidine $30 \mathrm{mg} / \mathrm{kg}$. In the $\mathrm{RE}+$ geraniin $30(30 \mathrm{mg} / \mathrm{kg})$ group, the esophageal erosions area of rats significantly decreased by more than $68 \%$ compared to the RE control group and the esophagus tissue damage of the RE rats was alleviated to a similar condition to that of the normal group by treatment with geraniin $30 \mathrm{mg} /$ $\mathrm{kg}$. Therefore, these results indicate that the geraniin has protective effects against esophagus damage in acute RE rats.
In the RE control group, the expression levels of both phosphorylated-IкB- $\alpha$ and phosphorylated-NF- $\mathrm{kB}$ protein were increased more by tissue damage than they were in the normal control group. The result showed that the highest inhibitory effects of inflammatory proteins indicated in the ranitidine $30 \mathrm{mg} / \mathrm{kg}$ treatment and 15 and $30 \mathrm{mg} / \mathrm{kg}$ geraniin improved the esophageal inflammation by inhibiting the expression of cytosolic COX-2, TNF- $\alpha$ and IL-1 $1 \beta$, especially at $30 \mathrm{mg} / \mathrm{kg}$ (Fig. 5). Several studies have been reported that the expression of proinflammatory cytokines and enzymes such as TNF- $\alpha$, IL- $1 \beta$, iNOS, COX-2 genes demonstrated in the damage tissue and it was related to degree of damage [24, 26, 27]. Thus, we found that geraniin was protects mucosa membranes via inhibiting pro-inflammatory proteins of NF- $\kappa B$ pathway signal on damaged esophagus in RE rats.

Claudin, one of the TJP in the epithelium and endothelium, was exerts critical barrier function of the tight junction. The expression of claudin- 4 and claudin- 5 was highest in normal control, in contradistinction to RE control (Fig. 6). Also, as an esophageal erosions decreased, the expression of claudin- 4 and claudin-5 proteins were increased by concentration-dependent manner 
on esophagus tissue in a RE rat model. The regulating of claudin proteins in the damaged cells and tissue has been reported in experimental gastro-esophageal reflux disease $[8,28]$. We found that the expression of claudin- 4 and claudin- 5 were all increased by concentration-dependent and significantly higher in pre-treated ranitidine and geraniin $30 \mathrm{mg} / \mathrm{kg}$ group compared with RE control group. TJP interact with the intestinal immune system to maintain the mucosal immune system [29]. The study shows that geraniin was ameliorate the esophagus damage by reflux esophagitis via regulating an immunity systems and TJP in tissue.

This study was to demonstrate the ameliorating effects of geraniin on esophagus in RE. Anti-inflammatory effects of geraniin identified by inhibitory activity of NO production and iNOS expression on Raw 264.7 cells. In RE rat model, geraniin showed a protective effect on esophagus damage and decreased inflammatory cell infiltration and epithelial loss in mucosa. In addition, we found that the defense mechanism underlying acid reflux-induced damage involved inflammatory processes, and geraniin protected the esophagus tissue by downregulating on NF-kB pathway signaling. Moreover, the expression of tight junction proteins in the esophagus tissue showed tendency to increase following geraniin treatment in RE rats. In the study, we identified the protective effects of geraniin on RE and can suggested that it could be safe alternative therapeutic source for inflammatory diseases.

\section{Authors' contributions}

BKC conceived and designed the experiments. HHN performed most of experiments and wrote the manuscript. LN and JCP conducted secondary experiment and data analysis. All authors read and approved the final manuscript.

\section{Author details}

${ }^{1}$ Department of Crop Science and Biotechnology, Chonbuk National University, Jeonju 54896, Republic of Korea. ${ }^{2}$ Bioenergy Crop Research Institute, Rural Development Administration National Institute of Crop Science, Muan 58545, Republic of Korea.

\section{Acknowledgements}

The work was supported by "Basic Science Research Program" through the National Research Foundation of Korea (NRF) funded by the Ministry of Education (2017R1D1A3B03036020).

\section{Competing interests}

The authors declare that they have no competing interests.

\section{Publisher's Note}

Springer Nature remains neutral with regard to jurisdictional claims in published maps and institutional affiliations.

Received: 1 November 2018 Accepted: 21 January 2019

Published online: 12 March 2019
References

1. Rhonda FS, Xiaofang H, Vivek M, Christopher MS, Susanne WC, Hui YZ, Xi Z, Chunhua Y, Kathy HC, Robert MG, Stuart JS (2009) Gastroesophageal reflux might cause esophagitis through a cytokine-mediated mechanism rather than caustic acid injury. Gastroenterology 137:1776-1784

2. Jabri MA, Tounsi H, Abdellaoui A, Marzouki L (2018) Protective effects of Artemisia campestris extract against gastric acid reflux-induced esophageal mucosa injuries. Pathophysiology 25:63-69

3. Badillo R, Francis D (2014) Diagnosis and treatment of gastroesophageal reflux disease. World J Gastrointest Pharmacol Ther 5(3):105-112

4. Kim TI (2015) The role of barrier dysfunction and change of Claudin expression in inflammatory bowel disease. Gut Liver 9(6):699-700

5. Rendon-Huerta E, Chavarria-Velazquez CO, Montano LF (2013) Claudins, inflammation and epithelial mesenchymal transition in gastric tissue. J Gastrointest Dig Syst 3:4

6. Miwa H, Koseki J, Oshima T, Kondo T, Tomita T, Watari J, Matsumoto T, Hattori T, Kubota K, lizuka S (2009) Rikkunshito, a traditional Japanese medicine, may relieve abdominal symptoms in rats with experimental esophagitis by improving the barrier function of epithelial cells in esophageal mucosa. J Gastroenterol 45:478-487

7. Lian B, Liu ZH, Wei HT, Zhang Z, Shi GN (2014) Protection effect Xuanfudaizhetang on reflux esophagitis in rats. Asian Pac J Trop Med 7:267-270

8. Gweon TG, Park JH, Kim BW, Choi YK, Kim JS, Park SM, Kim CW, Kim HG, Chung JW, Incheon and Western Kyonggi Gastrointestinal Study Group (2017) Additive effects of rebamipide plus protone pump inhibitors on the expression of tight junction proteins in a rat model of gastro-esophageal reflux disease. Gut Liver 12(1):46-50

9. Ward C, Schlingmann B, Stecenko AA, Guidot DM, Koval M (2015) NF-kB inhibitors impair lung epithelial tight junctions in the absence of inflammation. Tissue Barriers 3:1-2

10. Yu XT, Xu YF, Huang YF, Qu C, Xu LQ, Su ZR, Zeng HF, Zheng L, Yi TG, Li HL, Chen JP, Zhang XJ (2018) Berberrubine attenuates mucosal lesions and inflammation in dextran sodium sulfate induced colitis in mice. PLOS ONE 3(3):e0194069

11. Wang P, Qiao Q, Li J, Wang W, Yao LP, Fu YJ (2016) Inhibitory effects of Geraniin on LPS-induced inflammation via regulating NF-kB and Nrf2 pathways in RAW 264.7 cells. Chem Biol Interact 253:134-142

12. Mahattanadul S, Ridtitid W, Nima S, Phdoongsombut N, Ratanasuwon P, Kasiwong S (2011) Effects of Morinda citrifolia aqueous fruit extract and its biomarker scopoletin on reflux esophagitis and gastric ulcer in rats. J Ethnopharmacol 134:243-250

13. Xiao F, Zhai Z, Jiang C, Liu X, Li H, Qu X, Ouyang Z, Fan Q, Tang T, Qin A, Gu D (2015) Geraniin suppresses RANKL-induced osteoclastogenesis in vitro and ameliorates wear particle-induced osteolysis in mouse model. Exp Cell Res 330:91-101

14. Yang Y, Zhang L, Fan X, Qin C, Liu J (2012) Antiviral effect of Geraniin on human enterovirus 71 in vitro and in vivo. Bioorg Med Chem Lett 22:2209-2211

15. Wang X, Chen Z, Li X, Jiang ZK, Zhao YQ, Ping FF (2017) Geraniin suppresses ovarian cancer growth through inhibition of NF-kB activation and downregulation of $\mathrm{Mcl}-1$ expression. J Biochem Mol Toxicol. https://doi. org/10.1002/jbt.21929

16. Zhu G, Xin X, Liu Y, Huang Y, Li K, Wu C (2017) Geraniin attenuates LPSinduced acute lung injury via inhibiting NF-kB and activating Nrf2 signaling pathways. Oncotarget 8(14):22835-22841

17. Kwon OJ, Choo BK, Lee JY, Kim MY, Shin SH, Seo BI, Seo YB, Rhee MH, Shin MR, Kim GN, Park CH, Roh SS (2016) Protective effect of Rhei Rhizoma on reflux esophagitis in rats via Nrf2-mediated inhibition of NF-kB signaling pathway. BMC Complement Altern Med 16:7

18. Gupta S, Ahsan AU, Wani A, Khajuria V, Nazir LA, Sharma S, Bhagat A Raj Sharma P, Bhardwaj S, Peerzada KJ, Ali Shah B, Ahmed Z (2018) The amino analogue of $\beta$-boswellic acid efficiently attenuates the release of pro-inflammatory mediators than its parent compound through the suppression of NF-kB//kBa signalling axis. Cytokine 107:93-104

19. Akanda MR, Nam HH, Tian W, Islam A, Choo BK, Park BY (2018) Regulation of JAK2/STAT3 and NF-kB signal transduction pathways; Veronica 
polita alleviates dextran sulfate sodium-induced murine colitis. Biomed Pharmacother 100:296-303

20. Wu N, Zu Y, Fu Y, Kong Y, Zhao J, Li X, Li J, Wink M, Efferth T (2010) Antioxidant activities and xanthine oxidase inhibitory effects of extracts and main polyphenolic compounds obtained from Geranium sibiricum L. J Agric Food Chem 58(8):4737-4743

21. Kang JW, Lee SM (2014) Protective effects of chlorogenic acid against experimental reflux esophagitis in rats. Biomol Ther 22(5):420-425

22. Aayadi H, Mittal SPK, Deshpande A, Gore M, Ghaskadbi SS (2017) Cytoprotective effect exerted by Geraniin in HepG2 cells is through microRNA mediated regulation of $\mathrm{BACH}-1$ and $\mathrm{HO}-1$. Korean Soc Biochem Mol Biol 50(11):560-565

23. Akanda MR, Kim IS, Ahn DC, Tae HJ, Tian W, Nam HH, Choo BK, Park BY (2017) In vivo and in vitro hepatoprotective effects of Geranium koreanum methanolic extract via downregulation of MAPK/Caspase-3 Pathway. Evid Based Complement Altern Med 2017:8137627

24. Akanda MR, Park BY (2017) Involvement of MAPK/NF-kB signal transduction pathways: Camellia japonica mitigates inflammation and gastric ulcer. Biomed Pharmacother 95:1139-1146
25. Gyawali S, Khan GM, Lamichane S, Gautam J, Ghimire S, Adhikari R, Lamsal R (2013) Evaluation of anti-secretory and anti-ulcerogenic activities of avipattikar churna on the peptic ulcers in experimental rats. J Clin Diagn Res 7(6):1135-1139

26. Hatware KV, Sharma S, Patil K, Shete M, Karri S, Gupta G (2018) Evidence for gastroprotective, anti-inflammatory and antioxidant potential of methanolic extract of Cordia dichotoma leaves on indomethacin and stress induced gastric lesions in Wistar rats. Biomed Pharmacother 103(13):317-325

27. Katada K, Yoshida N, Isozaki Y, Tomatsuri N, Ichikawa H, Naito Y, Okanoue T, Yoshikawa T (2005) Prevention by rebamipide of acute reflux esophagitis in rats. Dig Dis Sci 50:S97-S103

28. Camire RB, Beaulac HJ, Willis CL (2015) Transitory loss of glia and the subsequent modulation in inflammatory cytokines/chemokines regulate paracellular claudin-5 expression in endothelial cells. J Neuroimmunol 284:57-66

29. Castoldi A, Favero de Aguiar C, Moraes-Vieira PM, Olsen Saraiva Câmara N (2015) They must hold tight: junction proteins, microbiota and immunity in intestinal mucosa. Curr Protein Pept Sci 16(7):655-671

\section{Submit your manuscript to a SpringerOpen ${ }^{\circ}$ journal and benefit from:}

- Convenient online submission

- Rigorous peer review

- Open access: articles freely available online

- High visibility within the field

- Retaining the copyright to your article

Submit your next manuscript at $\boldsymbol{\nabla}$ springeropen.com 